\title{
BUDAYA ORGANISASI, MOTIVASI, DAN KOMUNIKASI TERHADAP PRODUKTIVITAS KERJA KARYAWAN DINAS LINGKUNGAN HIDUP KABUPATEN WONOGIRI
}

\author{
Dwi Dian Putra Prasetio, Istiatin, Sri Hartono \\ Fakultas Ekonomi Manajemen, Universitas Islam Batik Surakarta \\ putrasatu995@gmail.com
}

\begin{abstract}
The aim of this research are 1) to find out the simultaneous influence between organizational culture, motivation, and communication on the employee productivity of the environmental services in Wonogiri Regency, 2) to determine in partial organizational culture, motivation and communication the effect on the employee productivity of the environmental services in Wonogiri Regency. The population in this study were all employees at the Wonogiri Regency Environmental Agency, which numbered 286 employees. The samples in this study were 86 respondents. Data collection techniques in this research were using observation, documentation, and questionnaires. Technical data analysis in this research were using classic assumption test, multiple linier test, $t$ test, $f$ test, the coefficients determined. The result of this study: 1) There is a simultaneous influence of organizational culture, motivation, and communication on the work productivity of Wonogiri District's environmental officers. 2) in partial variable organizational culture, motivation and communication give significant effect on employee productivity of the of the environmental services in Wonogiri Regency.
\end{abstract}

Key words : Organizational Culture, Motivation, Communication, Employee Productivity.

\section{PENDAHULUAN}

Pada era globalisasi ini, produktivitas selalu dipandang sebagai suatu mutu kehidupan yang harus ditingkatkan setiap harinya. Produktivitas kerja adalah kemampuan setiap individu dalam melaksanakan tugas yang diberikan kepadanya, sehingga ia akan mampu memberikan yang terbaik untuk perusahaan dimana ia bekerja. Semakin baik suatu perusahaan itu dikalangan bisnis dan pesaingnya, maka sudah pasti mereka memiliki karyawan atau pegawai dengan kinerja yang baik. Maka dari itu, perusahaan sebaiknya memahami dan mencari faktor apa saja yang dapat meningkatkan produktivitas kerja karyawan mereka.

Beberapa faktor yang diduga dapat meningkatkan produktivitas kerja antara lain ialah yang pertama budaya organisasi. Budaya organisasi ialah sekumpulan nilai dalam suatu organisasi yang dapat membantu karyawan dalam mengenal perusahaan yang mereka jalani. Semakin tinggi kepahaman mereka, maka semakin tinggi pula kemampuan mereka dalam bekerja dan memberikan hasil yang terbaik bagi perusahaan. Selanjutnya, faktor kedua ialah motivasi. Motivasi dapat diartikan sebagai suatu dorongan yang dilakukan untuk melakukan sesuatu, dalam hal ini tentu saja dorongan agar karyawan dapat terus meningkatkan produktivitas kerjanya dan memberikan hasil yang terbaik bagi keuntungan perusahaan. Selanjutnya faktor yang ketiga ialah komunikasi. Komunikasi adalah sebuah cara menyampaikan pesan kepada satu 
sama lain. Ketika seseorang bekerja dalam suatu perusahaan, maka dia harus bisa bekerja dalam sebuah tim. Oleh karena itu komunikasi harus terus dijaga agar hubungan yang baik selalu tercipta, sehingga pekerjaan dapat diselesaikan dengan baik.

Lokasi yang dipilih untuk penelitian ini adalah Dinas Lingkungan Hidup Kabupaten Wonogiri. Adapun obyek yang diteliti adalah pegawai atau karyawan Dinas lingkungan hidup kabupatern wonogiri.

\section{TINJAUAN TEORITIS}

\subsection{Produktivitas Kerja}

Menurut Hasibuan (2012; 23), Produktivitas adalah meningkatkan output (hasil) yang ssejalan dengan input (masukan). Jika produktivitas naik ini hanya dimungkinkan oleh adanya peningkatan efeisiensi (waktu,bahan,tenaga) dan sistem kerja, teknik produksi dan adanya peningkatan keterampilan dari tenaga kerjanya.

Produktivitas kerja menurut siagian $(2014 ; 17)$ adalah kemampuan menghasilkan barang jasa dari berbagai sumber daya dan kemapuan yang dimiliki oleh setiap pekerja/karyawan.

Produktivitas kerja menurut Jakson $(2014 ; 17)$ mengatakan bahwa ada empat aspek yang menentukan besar kecilnya produktivitas kerja seseorang, antara lain :

1) Keterampilan: dimana setiap pegawai ingin dengan segera menyelesaikan pekerjannya dan memiliki motivasi untuk berkembang.

2) Kemampuan: berusaha meningkatkan kemampuan dan kualiatas kerja.

3) Sikap: memiliki seikap yang siap dan sigap serta loyalitas dalam bekerja.

4) Perilaku: dimana setiap pekerja selalu ingin meningkatkan hasil produksi dan setiap pekerja selalu bekerjasama dalam berbagai hal.

\subsection{Budaya Organisasi}

Gibson (Febriana, 2016;75) mendefinisikan budaya organisasi sebagai sistem yang menembus nilai-nilai, keyakinan, dan norma yang ada disetiap organisasi. Kultur organisasi dapat mendorong atau menurunkan efektifitas tergantung dari sifat nilai-nilai, keyakinan dan norma-norma yang dianut.

Menurut Moorheda dan Griffin (Febriana, 2016;78), budaya organisasi merupakan kumpulan nilai-nilai yang membantu anggota organisasi memahami tindakan yang dapat diterima dan mana yang tidak dapat diterima dalam organisasi.

Fungsi budaya organisasi menurut Robbins (2013:69) memiliki empat fungsi yaitu :

1) Budaya mempunyai suatu peran pembeda.

2) Budaya organisasi membawa suatu rasa identitas bagi anggota-anggota organisasi.

3) Budaya organisasi mempermudah timbul pertumbuhan komitmen pada sesuatu yang lebih luas daripada kepentingan diri individual.

4) Budaya organisasi meningkatkan kemantapan sistem social. 


\subsection{Motivasi}

Menurut Robbins (2013:166) definisi dari motivasi yaitu kesedian untuk mengeluarkan tingakat upaya yang tinggi untuk tujuan organisasi yang dikondisikan oleh kemampuan upaya itu untuk memenuhi beberapa kebutuhan individual.

Sedangkan Hasibuan $(2011 ; 141)$ berpendapat bahwa motivasi adalah hal yang menyebabkan, menyalurkan dan mendukung perilaku manusia, supaya mau bekerja giat dan antusias mencapai hasil yang optimal.

Indikator motivasi kerja menurut Sunyoto (2013: 13) :

1. Promosi

2. Prestasi kerja atau keberhasilan dalam bekerja

3. Pekerjaan itu sendiri

4. Penghargaan/ Pengakuan

5. Tanggung jawab

\subsection{Komunikasi}

Menurut Steiner (dalam Ivony, 2017) Komunikasi : transmisi informasi, gagasan, emosi, keterampilan dan sebagainya dengan menggunakansimbol-simbol, kata-kata, gambar, dam sebagainya.

DeVito $(2011 ; 24)$ dalam bukunya menyatakan bahwa "Komunikasi mengacu pada tindakan, oleh satu orang atau lebih, yang mengirim dan menrima pesan yang terdistrosi oleh gangguan.

Unsur-unsur Komunikasi yang penting menurut Lasswel (dalam Nasriaika, 2014), yaitu : sumber, pesan, penerima, efek.

\subsection{Kerangka Penelitian}

Untuk mempermudah pemahaman dan memperjelas penelitian maka dapat digambarkan suatu kerangka penelitian teoritis sebagai berikut :

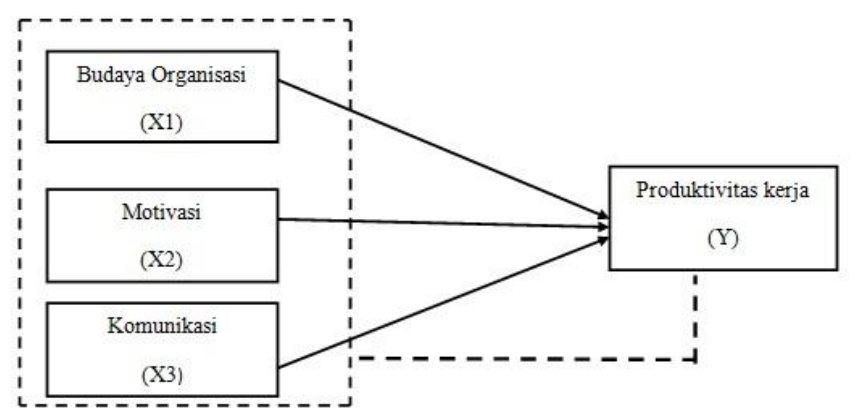

Dinas Lingkungan Hidup Kabupaten Wonogiri ternyata dipengaruhi oleh variabel independen yaitu budaya organisasi (X1), Motivasi (X2), dan Komunikasi (X3) terhadap variabel dependen yaitu produktivitas kerja (Y) yang ditunjukan dengan garis lurus. Ada juga pengaruh simultan dari variabel independen terhadap variabel dependen yang ditunjukan dengan garis putus-putus. 


\subsection{Hipotesa}

1) Diduga Budaya organisasi, motivasi dan komunikasi berpengaruh signifikan terhadap Produktivitas Kerja Karyawan Dinas Lingkungan Hidup Kab. Wonogiri

2) Diduga Motivasi pegawai berpengaruh positif dan signifikan terhadap Karyawan Dinas Lingkungan Hidup Kab. Wonogiri..

3) Diduga Komunikasi berpengaruh positif dan signifikan terhadap Karyawan Dinas Lingkungan Hidup Kab. Wonogiri.

4) Diduga Budaya Organisasi berpengaruh positif dan signifikan terhadap Produktivitas Kerja Karyawan Dinas Lingkungan Hidup Kab. Wonogiri.

\section{METODE PENELITIAN}

\subsection{Populasi dan Sampel}

Populasi dalam penelitian ini adalah seluruh pegawai yang ada di Dinas Lingkungan Hidup Kabupaten Wonogiri yang berjumlah 286 pegawai. Sampel adalah sebagian atau wakil dari populasi yang diteliti (Arikunto 2010: 174). Sampel dalam penelitian ini adalah 86 responden. Teknik sampling yang digunakan dalam penelitian ini adalah probability sampling, adapun teknik problability sampling yang digunakan adalah simple random sampling.

\subsection{Metode Pengumpulan data}

Dalam penelitian ini, peneliti menggunakan beberapa metode, yaitu: observasi mengamati sekaligus pencatatan secara sistematik segala aktivitas kinerja pegawai, dokumentasi menganalisis isi dokumen yang berhubungan dengan masalah yang diteliti, angket atau kuesioner.

\subsection{Model dan Teknik Analisis}

Pendekatan penelitian yang digunakan dalam penelitian ini adalah menggunakan analisis deskriptif dengan pendekatan kuantitatif. Untuk menguji pengaruh variable independen terhadap variable dependen baik secara parsial maupun simultan menggunakan analisis regresi linear berganda. Berikut bentuk persamaan regresi dalam penelitian ini: ((Ghozali (2009: 17))

$$
\begin{aligned}
& \mathrm{Y}=\mathrm{a}+b_{1} X_{1}+b_{2} X_{2}+\mathrm{b}_{2} \mathrm{X}_{3}+\mathrm{e} \\
& \text { Keterangan : } \\
& \mathrm{Y} \quad=\text { Produktivitas kerja } \\
& \mathrm{a} \quad=\text { Konstanta } \\
& \mathrm{bn} \quad=\text { Koefisien regresi variabel bebas ke- } \mathrm{n} \\
& x_{1} \quad=\text { Variabel budaya organisasi } \\
& x_{2} \quad=\text { Variabel motivasi } \\
& \mathrm{x}_{3} \quad=\text { Variabel komunikasi } \\
& \mathrm{e} \quad=\text { Variabel pengganggu (error) }
\end{aligned}
$$


Selanjutnya dilakukan uji F, uji T, dan koefisien determinasi.

\subsection{Pengujian Hipotesis}

Untuk menguji hipotesis nomer 1 peneliti menggunakan uji F, Uji F digunakan untuk menguji koefisien regresi secara simultan atau bersama-sama antara variabel independen dengan variable dependen. Penilaian dengan melihat nilai Fhitung. Jika fhitung < nilai F table, maka Hipotesis penelitian diterima. Dalam penelitian ini, hasil uji $\mathrm{F}$ menerangkan sejauh mana pengaruh bersama-sama budaya organisasi, motivasi, dan komunikasi terhadap produktivitas kerja. Untuk melihat besarnya perilaku karyawan dalam menjalankan pekerjaan dapat dilihat dari besarnya koefisien determinasi. Kemudian, nilai t hitung dilakukan untuk melihat pengaruh secara parsial antara variable independen terhadap variable dependen. Penilaian dilihat dari nilai thitung. Jika nilai thitung lebih besar dari ttabel, maka hipotesis diterima.

\section{HASIL PENELITIAN DAN PEMBAHASAN}

\subsection{Hasil Penelitian}

Hasil perhitungan analisis regresi berganda dengan menggunakan SPSS 17 disajikan dalam table berikut:

\begin{tabular}{|c|c|c|c|c|c|}
\hline & 1. Hasi & Analisis Reg & resi Berganda & & \\
\hline \multirow[b]{2}{*}{ Model } & \multicolumn{2}{|c|}{$\begin{array}{l}\text { Unstandardized } \\
\text { Coefficients }\end{array}$} & \multirow{2}{*}{$\begin{array}{c}\begin{array}{c}\text { Standardized } \\
\text { Coefficients }\end{array} \\
\text { Beta }\end{array}$} & \multirow[b]{2}{*}{$\mathrm{T}$} & \multirow[b]{2}{*}{ Sig. } \\
\hline & B & Std. Error & & & \\
\hline 1 (Constant) & 17.022 & 3.447 & & 4.938 & .000 \\
\hline $\begin{array}{l}\text { BUDAYA } \\
\text { ORGANISASI }\end{array}$ & -.388 & .140 & -.256 & -2.772 & .007 \\
\hline MOTIVASI & .278 & .067 & .389 & 4.138 & .000 \\
\hline KOMUNIKASI & .495 & .130 & .348 & 3.808 & .000 \\
\hline $\begin{array}{l}\text { a. Dependent Variable: } \mathrm{P} \\
\mathrm{F}_{\text {hitung }}=14,215 \\
\mathrm{~F}_{\text {tabel }}=3,11 \\
\mathrm{~T}_{\text {tabel }}=1,98 \\
\mathrm{R} \text { square }=0,342\end{array}$ & KTIVITAS & KERJA & $\begin{array}{l}\mathrm{n}=86 \\
\operatorname{sig}=0,000\end{array}$ & & \\
\hline
\end{tabular}

Sesuai dengan hasil analisis regresi linier berganda sebagai berikut :

$$
\mathrm{Y}=17,022+-0,388 \mathrm{X}_{1}+0,278 \mathrm{X}_{2}+0,495 \mathrm{X}_{3}+\mathrm{e}
$$

Hasil tersebut menunjukkan bahwa Budaya organisasi, Motivasi Kerja dan variabel komunikasi berpengaruh sigifikan terhadap variabel produktivitas Kerja. Sedangkan dari hasil uji $\mathrm{t}$ dapat diperoleh variabel budaya organisasi dengan nilai $\mathrm{t}_{\text {hitung }}=-2,772>\mathrm{t}_{\text {tabel }}=1,9893$, maka Ho ditolak sehingga ada pengaruh yang signifikan Budaya organisasi terhadap produktivitas kerja. 
Motivasi Kerja dengan nilai $\mathrm{t}_{\text {hitung }}=4,138>\mathrm{t}_{\text {tabel }}=1,9893$, maka Ho ditolak sehingga ada pengaruh yang signifikan Motivasi Kerja terhadap produktivitas Kerja. Dan perhitungan variabel komunikasi diperoleh hasil $t_{\text {hitung }}=3,808>t_{\text {tabel }}=1,9893$, maka Ho ditolak sehingga ada pengaruh yang signifikan komunikasi terhadap produkyivitas Kerja. Begitu juga dari hasil perhitungan uji $\mathrm{F}$ dapat diperoleh diperoleh nilai $\mathrm{F}_{\text {hitung }}=14,215>\mathrm{F}_{\text {tabel }}=3,11$, maka Ho ditolak sehingga secara bersama-sama ada pengaruh yang signifikan budaya organisasi $\left(\mathrm{X}_{1}\right)$, Motivasi Kerja $\left(\mathrm{X}_{1}\right)$, komunikasi $\left(\mathrm{X}_{2}\right)$ terhadap produktivitas Kerja.

\subsection{PEMBAHASAN}

Hasil analisis deskriptif dan pengujian hipotesis menunjukkan bahwa variabel budaya organisasi, motivasi dan komunikasi secara simultan berpengaruh signifikan terhadap produktivitas kerja karyawan dan secara parsial menunjukkan bahwa variabel budaya organisasi berpengaruh terhadap produktivitas kerja. variabel motivasi berpengaruh terhadap produktivitas kerja.. variabel komunikasi berpengaruh terhadap produktivitas kerja.

\section{KESIMPULAN DAN SARAN}

\subsection{Kesimpulan}

1) Ada pengaruh secara simultan budaya organisasi, motivasi, dan komunikasi terhadap produktivitas kerja pegawai dinas lingkungan hidup Kabupaten Wonogiri.

2) Ada pengaruh signifikan Budaya Organisasi terhadap Produktivitas Kerja pegawai Dinas Lingkungan Hidup Kabupaten Wonogiri.

3) Ada pengaruh signifikan Motivasi Kerja terhadap Produktivitas Kerja pegawai Dinas Lingkungan Hidup Kabupaten Wonogiri.

4) Ada pengaruh signifikan komunikasi terhadap Produktivitas Kerja pegawai Dinas Lingkungan Hidup Kabupaten Wonogiri

\subsection{Saran}

Berdasarkan analisis dan kesimpulan, maka dapat disampaikan saran-saran sebagai berikut:

1) Hasil analisis data menunjukkan adanya pengaruh yang signifikan antara Budaya Organisasi, Motivasi Kerja dan Komunikasi terhadap Produktivitas Kerja, maka perlu diperhatikan atau perlu ditingkatkan lagi oleh Dinas Lingkungan Hidup Kabupaten Wonogiri.

2) Dinas Lingkungan Hidup Kabupaten Wonogiri dalam usaha meningkatkan Produktivitas Kerja karyawan, maka perusahaan seyogyanya meningkatkan Motivasi Kerja dengan memberikan penghargaan baik berupa promosi jabatan.

3) Dinas Lingkungan Hidup Kabupaten Wonogiri dalam usaha meningkatkan Produktivitas Kerja karyawan, maka perusahaan seyogyanya memperhatikan komunikasi antar karyawan yang selaras. 


\section{REFERENSI}

Arikunto, Suharsimi. 2010. Prosedur Penelitian Suatu Pendekatan Praktik. Edisi Revisi 2010. Jakarta: PT. Rineka Cipta.

DeVito, A Joseph. 2011. Komunikasi antar Manusia. Tangerang: Karisma.

Ghozali, Imam. 2006. Aplikasi Analisis Multivariated Dengan Program SPSS. Edisi Cetakan IV. Semarang: Badan Penerbit Universitas Diponegoro.

Hasibuan, Malayu, S.P. 2011. Organisasi dan Motivasi Dasar Peningkatan Produktivitas. Jakarta: Bumi Aksara.

Jackson, dkk. Pengelolaan Sumber Daya Manusia. Jakarta : Salemba empat.

Robbins, Stephen P. 1998 Perilaku Organisasi, Edisi Bahasa Indonesia cetak ke 2, Prenhalindo, Jakarta.

Siagian, S.P. 2014. Manajemen Sumber Daya Manusia. Jakarta: Bumi Aksara.

Sunyoto, Danang. 2013. Teori, Kuesioner, dan Analisis Data Smber Daya Manusia (Praktik Penelitian). Yogyakarta: CAPS.

Febriana, Misna. 2016. Pengertian Budaya Organisasi

(http://misnafebriana96.blogspot.com/2016/11/pengertian-budaya-organisasi-

indikator.html?m=1)

Ivony. 2017. 35 Pengertian Komunikasi Menurut Para Ahli,

(http://pakarkomunikasi.com/pengertian-komunikasi-menurut-para-ahli/amp)

Nasriaika. 2014. Model Komunikasi Lasswell.

(https://nasriaika1125.wordpress.com/2014/03/30/model-komunikasi-lasswell/ 